\title{
An Analysis on Mechanism and Motivation of Intergenerational Transmission of Human Capital HU Weihua
}

\author{
College of Economics, Inner Mongolia Normal University, Hohhot, Inner Mongolia, 010022, China
}

Keywords: Human capital intergenerational transmission; Mechanism; Motivation

\begin{abstract}
Currently, our country is in the period of social transition, the widening gap between the rich and the poor, social class curing are directly related to intergenerational transmission of human capital. This paper, from the perspective of economics, combining discipline sociology, and behavioral science knowledge, analyses the mechanism and motivation of intergenerational transmission of human capital, and discusses the motivation practical application of intergenerational transmission of human capital in our country.

At present, China is in a period of social transformation, the gap between rich and poor is wider, social structure is harden, "second generation" is frequent, which are all questioning China's social fair mechanism, and the crux of the issue is closely related to the intergenerational transmission of human capital. From the theory of intergenerational transmission literature review of human capital at home and abroad, it is found that a large number of empirical research is developed in European and America developed countries data context, [1][2][3][4] research in developing countries is rarer, and Asia background research is lesser. Over more than 30 years China's reform and opening up, a unique model of socio-economic development is created and study on the intergenerational transmission of human capital in China should have a more typical significance. Research in our country more takes the intergenerational transmission of human capital as an explanatory variable of income, poverty and other issues' intergenerational transmission, [5][6][7][8] and less truly focuses on the theoretical issues such as mechanism, motivation and ways of intergenerational transmission of human capital. There is need for further study and exploration. From economics perspective, combining disciplines such as sociology, behavioral science knowledge, this paper analyzes mechanisms and incentive of intergenerational transmission of human capital.
\end{abstract}

\section{Human capital intergenerational transmission mechanism}

Economists tried to find evidence of intergenerational transmission from economic theory, which can include intergenerational transmission problem into economic analysis category, and can do more quantitative analysis and research, and provide the basis for economic policy formulation. From an economic point of view, the study of intergenerational is resource configuration issues across multiple generations. In intergenerational transmission of human capital, "resources" refer to educational achievement, health care and other human capital. Human capital intergeneration is completed through investment activities. Investments in human capital are mainly family support, public education, training, migration, of which the first two are the most common and most important investment activities, and these different types of investment main body determine that mechanisms of intergenerational transmission of human capital include both micro and macro levels.

\section{A. Micro-mechanism}

Family support, as well as most of migration decision, is without a doubt a direct family activity, which embodies micro delivery mechanism based on home. From micro-level study, intergenerational transmission of human capital is on the two dimensions of space and time. On the spatial dimension, intergenerational transmission mechanism takes family as the core; previous generations of family members have an impact on the formation of human capital of the next generation through investment in human capital activities. Like, trained parents of good education will in subjective wishes have more tendencies to let children accept good education, and invest 
more proportions on children education investment inputs, while parents of high human capital will more have high income career, thus also more have capacity to let its children accept higher education or other conducive investment behavior for human capital formation, also, trained good education parents establish social capital which also may let their children benefit from human capital formed. Seen from the time dimension, intergenerational transmission occurs in almost all stages of life cycle, as long as there are adjacent two generations, intergenerational transmission will happen. Whether a parent or a child generation, their lives include their own childhood and adolescence, youth, middle age, old age stages, various stages consumption and demand characteristics are very different, at different stages, the life cycle of an adjacent two generations will overlap each other, and form different connotation transmission behavior.

\section{B. Macro mechanism}

From macro-level visits, macro mechanisms of intergenerational transmission cannot be understood as the simple sum of microcosmic mechanism, and also consider the effects of government intervention and public policy. Intergenerational transmission involves a growing number of "public goods", and government intervention and public policy will continue to expand the scope. Public education is run by the Government; decision-making of public education investment level is the result of total balance of Government macroscopic policy decision, and has obvious characteristic of intergenerational transmission, so there must be a macro mechanism of intergenerational transmission of human capital.

Micro-mechanism and macro-mechanism of intergenerational transmission of human capital interact and affect each other, and macro policies play a role through micro mechanisms (individuals and families), and micro-mechanism affects appropriate macroeconomic policies. Macro mechanism represented by public investment in education, from the perspective of financial flows, is a "transfer payment" behavior, and the macro-level of intergenerational transmission of human capital also is on a household basis.

\section{Intergenerational transmission motivation of human capital}

In intergenerational transmission of human capital, there is an implied assumption about intergenerational transmission motivation of human capital, whose original is rooted in the most basic assumptions of Western economics - "economic man" hypothesis. Adam Smith is the first in the history of Economics, most beautifully presented a pattern of economic behavior, through continuous improvement and conceptualization; it has become one of Western economics "axiom". But in practice, economists have not stopped questioning and debating on "economic person" assume, instead "economic man" assumption, after repeated exercise, won several major revision and development, which continuously improved and made this assumption closer to reality. [9]

"Economic person" assume persistence and questioning mainly revolve motives of human behavior which is "all" or "altruistic". Theoretically, it tends to think that parents' children's human capital investment motives might be: exchange motives and altruistic motives. Exchange motivation means that parents expect to obtain returns from children human capital investment, selfish parents care children's future potential income level, and subjectively think the higher children human capital level, the stronger potential profit capacity; when parents are old with declined income and poor health status, they expect to obtain compensation from children high income, which is often reflected the thought of "depend on children when old". Therefore under exchange motives, parents' children human capital investment is based on a commitment made by or under the psychological contract of mutual decisions. Altruistic doctrine motivation means that parents' human capital investment on children is the consideration of happiness and welfare of children's future (Becker, 1991). [10] According to motivation strength, it is divided into purely altruistic doctrine motivation (parents only considered children welfare and not care inputs and returns) and limited altruistic doctrine motivation (while parents training children, he will obtain happiness). 
Driven by altruistic motives, parents get value-added utility because the child is the future of utility. As long as the child is greater than the marginal utility of consumption in the future, parents marginal utility of consumption, intergenerational transfer behavior will occur (Cox,1987;Kotlikoff \& Morris, 1989). Different motives of intergenerational transmission imply the awareness of equity, efficiency, and growth. [11] [12]

In fact, human capital intergenerational transfer behavior based on family is very complex, and it is not possible in pure self-interest or altruism to make a judgment and selfish motives and altruistic motives are not "either or trade-off", that unselfishness will not necessarily altruistic, the same token, not altruism is not necessarily egoism.

Pattern one: self-interest and mutual benefit. This behavior can also have two points, one is selfinterest as the starting point, and the other is to facilitate the people as the starting point. To selfinterest for starting point usually can be considered an exchange behavior, as parents select to invest children human capital, and expect to obtain returns; selfish parents care of children future potential income level, and subjectively think the higher children human capital level, the stronger its potential profit capacity. Based on altruistic motives, it can be regarded as a limited form when parents' target can be defined as $\Pi+U P$, where $U$ is the coefficient of self-satisfaction, namely the effectiveness of parents to send their children to achieve their own goals and then consider their utility to achieve.

Mode II: altruistic acts with self-sacrifice. This behavior can also be considered an act of pure altruistic motives, such as completely child-centric parents who devote their attention to children's future well-being and not concerned with their own return on investment and, even to their own health, time and pay in exchange for more for their children's physical and mental capital accumulation. Practice has proved that paying parents are unlikely to produce success for their children, even children are successful, they would also be guilty because of parents' sacrifices, and reduce the feeling of success. In real life, completely altruistic behavior only applies to one-way gifts and gratuitous acts of self-sacrifice, and will not necessarily bring real benefits to each other to improve.

Model III: self-interested behavior at the expense of others interests. If parents desire to satisfy their own material wishes, while ignoring or even encroaching on funding for children to receive education or instilling wrong values to guide their children, these actions can only be a short-term increase in the utility, and in the long run, they will make the family's overall effect decline, not conducive to growing family.

Pattern IV: Manger's counterproductive behavior. Parents in the family use human capital investment funds which could have been used for home improvements for bad behaviors such as gambling, drug abuse, and eventually damage their health, quality of life, image and so on, and will harm their children's future growth.

Obviously, among the four kinds of behavior a mode, only mutual benefit model is the most efficient, and has the best outcome, purely selfish behavior and completely altruistic behavior will not lead to the best results.

\section{Intergenerational transmission motivation of human capital in our practice in China}

Under the influence and practical constraints of traditional culture, only under mutually beneficial patterns of intergenerational transmission of human capital, household utility maximization can be produced, and the starting point or underlying motives for this mutually beneficial should be driven by altruism. This is based on:

A. In intergenerational transmission decision-making within family, ethical sentiment dominates, and easily evokes altruistic motives.

Because "he" here is not who is unrelated, "he" is with his own genetically related and unrelated people, "altruism" is sometimes a kind of instinct. 
B. Chinese society has its own cultural tradition and intergenerational issues become more diversified.

Different from the West relay-style patterns $\left(F_{1} \rightarrow F_{2} \rightarrow F_{3} \rightarrow F_{4}\right)$ of parent-child relationship, China's parent-child relationship model is the feedback mode: $F_{1} \gtrless_{2} \gtreqless F_{3} \leftrightarrow$ is for raising, $\leftarrow$ is maintenance). [13] Chinese family intergeneration exchange is in parent-child two generation, exchange form is based on mutual interests for material, emotional and spirit exchange, and different from material exchange, emotional and spirit exchange cannot be quantitative, that is what we called "parents goodness", while this exchange is to continued down in a way of intergeneration, and is interwoven with Chinese social favors, face, culture rules together, and forms more diversified intergeneration relationship. Although intergenerational exchanges are based on mutual interests, this win is not equivalent; in General, parents pay for their children is bigger than children returns on their parents. As shown in Figure 1, in a standard three-generation families in intergenerational relations, an adult child is both grace and mercy, under the effects of delivery mode inherited from their parents, their main focus is raising, gracing the next generation, maintenance care returns for elderly parents are rare part of impossible to peer about their pay. But elderly parents will not reduce the emotional or physical pain of adult children and grandchildren generation, so every generation gain more from parents than their return. Unequal mutual benefit relations of intergenerational exchange may last. In this sense, Chinese family's intergenerational exchange motives should be driven by altruistic motives. Judging from the relationships between three generations or more generations, intergenerational exchange produces some kind of equivalence, but measured in the longer term significant emotional and spiritual gain, rather than measured only provisionally in terms of material benefits.

C. When introduce social gender perspective to examine intergenerational transmission motivation of human capital, it also varies.

Chinese family relationship is in a parent-child relationship for the spindle, and the continuity is based on axis of basic characteristics of parent-child relationships. Each set of parent-child relationships is one link in the chain of parent-child relationships. In this mode, father's children human capital investment expectation is that children becomes useful, and is the honor of ancestors, and the family, and their children's human capital investment is a commitment based on exchange motives or make mutual decisions under psychological contract. And a mother's investment for her children human capital is even simpler, direct and pure, that she wants her children to have a better life in the future benefits. So to some extent, we may judge: male (father) motives tend to be based on self-interest and mutual and beneficial patterns, while women (mothers) are more inclined to altruism as the starting point, that is mutually beneficial pattern or pure altruistic motives.

Anyway, based on family, human capital intergeneration pass behavior motivation occurred is complex, in China culture background, human capital intergeneration pass motivation more reflects an altruistic doctrine motivation with more moving of mutual behavior, parents utility gets valueadded due to children future utility, invested children human capital not only makes family total utility value-added, also will prompt society human capital stock obtain higher accumulated level.

1. Inner Mongolia social science planning project "Women's Human Capital and Social Development Research in Inner Mongolia" project number: 2011B040;

2. Inner Mongolia social science planning fund project "Chinese Women's Comparative Study of Intergenerational Transmission of Human Capital" project number: 2014F160

\section{References}

[1] Björklund, Lindahl \& Plug. Intergenerational effects in Sweden: what can we learn from adoption data?. IZA Discussion Papers 1194, Institute for the Study of Labor. 2004. 
[2] Helmuth Cremer, Pierre Pestieau. Intergenerational Transfer of Human Capital and Optimal Education Policy. Journal of Public Economic Theory. 2006, 8(4): 529-545.

[3] James McIntosh, Martin D. Munk. Scholastic ability vs family background in educational success: evidence from Danish sample survey data. Journal of Population Economics. 2007, 20:101-120 .

[4] Philipp Bauer \& Regina T. Riphahn. Education and its intergenerational transmission: country of origin-specific evidence for natives and immigrants from Switzerland. Portuguese Economic Journal, 2006, 5:89-110.

[5] Ma Xin. Education fair effect on international transmission power cutting [J]. Modern Education Management, 2009(1):19-22.

[6] Lin Sen, Shan Lili. Education opportunity equality and low-income group intergenerational continuity relationship analysis[J]. Journal of Human BBS, 2010(5):109-112.

[7] $\mathrm{Hu}$ Yingsen. Our country low-income family children higher education investment research[J]. Probe, 2012(7):256-257.

[8] Guo Congbin, Min Weifang. Education: creating reasonable intergenerational mobility mechanism, structural equation model in the study of relationship between education and intergenerational mobility applications [J]. Journal of Education Research, 2009(10):5-12.

[9] Liang Hongxue. "Economic man" hypothesis theory of evolution and development, evaluation of the objectivity of "economic man" hypothesis[J]. Journal of Jianghan BBS, 2003(7):41-45.

[10] Becker G.S. A Treatise on the Family. Cambridge, Harvard University Press, Massachusetts. 1991.

[11] Cox D. Motives for private income transfers, Journal of Political Economy, 1987, 95: 508-546.

[12] Kotlikoff, Morris. How much care do the aged receive from their children in the economics of aging, Wise (ed.), Chicago, University of Chicago Press. 1989.

[13] Fei Xiaotong. The elderly support issues in family structure changing: Chinese structure change reconsideration[J]. Journal of Peking University(Philosophy and social sciences edition), 1983(3): 6-15. 